\title{
Mídia, identidade e território: as cidades projetadas pelos formatos noticiosos no telejornalismo local
}

\author{
Jhonatan Alves Pereira Mata - jhonatanmata@yahoo.com.br \\ Universidade Federal de Juiz de Fora (UFJF) \\ Jornalista e mestre em Comunicação (UFJF). Funcionário da Faculdade de Comunicação da UFJF. \\ IlUSKA MARIA DA SILVA CoUTINHO - iluskac@uol.com.br \\ Universidade Federal de Juiz de Fora (UFJF) \\ Jornalista, doutora em Comunicação Social (Umesp) e mestre em Comunicação e Cultura (UnB). Professora da \\ Departamento de Jornalismo e do Mestrado da Faculdade de Comunicação da UFJF.
}

\begin{abstract}
Resumo
O trabalho estuda as estratégias narrativas típicas empregadas pelas equipes dos telejornais locais ao se dirigirem ao seu "público imaginado". Interessou-nos perceber como as rotinas de trabalho dos profissionais são mobilizadas para maximizar os processos de identificação entre as propostas discursivas ofertadas via televisão e as múltiplas narrativas de Juiz de Fora e da região. O recorte empírico constituiu-se de análise dos formatos noticiosos e temáticas preferencialmente utilizados pelos três atuais telejornais locais de horário noturno gerados em Juiz de Fora, ao configurarem, na tela, seus espaços urbanos.
\end{abstract}

\section{Palavras-chave}

Telejornalismo. Identidade. Cidade. Formatos noticiosos.

\begin{abstract}
The paper studies the typical narrative strategies employed by the local TV news teams are directed to their "imagined audience". It interested us to see how the work routines of professionals are deployed to maximize the process of identification between the discursive proposals offered via television and the multiple narratives of Juiz de Fora and region. The crop consisted of empirical analysis of news formats and thematic preferably used by three local TV news today evening hours generated in Juiz de Fora, to set up, on screen, its urban spaces.
\end{abstract}

\section{Keywords}

Television news. Identity. City. News format.

Artigo recebido em 20/09/2011

Aprovado em 19/10/2011 
$\mathrm{N}$ o percurso histórico do telejornalismo em Juiz de Fora, diferentes emissoras como as TVs Industrial, Tiradentes e Mariano Procópio e as atuais TVs Panorama, Educativa e Alterosa procuram estabelecer representações da cidade e, por consequência, relações de pertencimento com os juizforanos. $\mathrm{Na}$ análise deste "sentimento de pertença", compreendemos que os meios de comunicação de massa conquistaram um lugar relevante de significado cultural e social na sociedade contemporânea. No caso específico de Juiz de Fora, esse "laço social" (WOLTON, 1996) se materializa na produção de programas que reforçam (e reforçavam) traços e mitos fundadores presentes na identidade e cultura do próprio município, como o pioneirismo e a efervescência industrial e cultural da "Manchester Mineira".

A comparação com a famosa cidade industrial inglesa se deve, sobretudo, ao salto econômico vivenciado por Juiz de Fora a partir de 1870, indo até as primeiras décadas do século passado. Foram muitos os empreendimentos e as conquistas. Em 1870, a cidade tem seu primeiro telégrafo, o seu primeiro jornal, abre-se o banco Territorial Mercantil de Minas. São construídas as estradas de ferro Dom Pedro Segundo e Leopoldina. Os bondes e o telefone chegam em 1880. Em 1889, é a vez da instalação do Banco de Crédito Real. As indústrias se multiplicam, principalmente nos setores têxtil e de produção de alimentos. Em 1911, havia 58 indústrias em Juiz de Fora. Em 1921, já eram 107 estabelecimentos. Tanto desenvolvimento só poderia levar a essa comparação, que, conforme veremos, tenta ser mantida enquanto discurso (telejornalístico ou não) até a atualidade.

A mídia, nesse sentido, analisada sob a ótica do telejornal, tanto em esfera local quanto nacional, se constitui atualmente como nova "praça pública" (COUTINHO, 2003), onde significativa parcela da população brasileira celebra senão o único, ao menos o mais importante encontro cotidiano com informações de caráter jornalístico. Parte-se do pressuposto de que os telejornais locais ancoram a representação da identidade juizforana por meio da utilização de características míticas da cidade, como seu espírito empreendedor e de vanguarda. Tais traços discursivos se manifestam no 
discurso veiculado sobre a própria população, que, inserida nos noticiários como "povo fala" e como personagens nas matérias, passa a ser (re)tratada como aquela que reclama, que exige restabelecimento de ordem (nas mais diversas esferas) para que o "progresso" da Manchester Mineira se viabilize. E mais: os telejornais locais, ao se utilizarem da participação popular, negociam, no fluxo do discurso audiovisual, as "realidades" ofertadas a cada edição, para garantir a adesão do cidadão e convertê-lo em telespectador.

Em Juiz de Fora, a narrativa sobre quem seria o "juizforano" é marcada por momentos de crise, conflito e contestação. Ao mesmo tempo em que se tenta estabelecer um discurso de tradicionalismo e provincianismo mineiro, marcado pela força da "vizinhança" e da religiosidade, a identidade juizforana tem seu viés de Manchester Mineira, focado na vanguarda e na negação da mineiridade tradicional, naquilo que poderíamos classificar como "não-mineiro", ou "forasteiro", na concepção estruturalista de Lévi-Strauss (SILVA, 2002, p. 49). No texto de Tomaz Tadeu da Silva, essa concepção binária entre identidade/diferença aparece na crítica que o autor realiza sobre o discurso atual de "respeito à diversidade". Isto porque, num contexto de "multiculturalismo", haveria a limitação de se tomar identidade e diferença como algo cristalizado, deixando-se de lado a crítica ao próprio caráter cambiante dos mesmos. Tomaz defende uma relação de dependência (e não de exclusão) entre estes dois conceitos.

Voltando a nossos exemplos locais, se alguém declara "sou juizforano", tal resposta afirmativa não se esgota em si mesma. Aqui, trabalha-se com uma "extensa cadeia de negações”(SILVA, 2002, p. 75), de identidades e diferenças, onde a "gramática" afirmativa ajuda a simplificar, mas também esconde essas muitas negações. Ser juizforano implica em "não ser belo horizontino", "não ser paulista", "não ser carioca”, dentre muitas outras não-respostas possíveis, conforme observaremos adiante, ao explicitarmos algumas das narrativas tecidas sobre a cidade. 


\section{Narrativa da Identidade local: criações, re-criações e representação da cidade de Juiz de Fora e do Juizforano}

Princesa de Minas. Manchester Mineira. Cosmopolita ou provinciana? Cosmopolita e provinciana? Quais os aspectos identitários que fazem (ou não) com que os juizfornanos se reconheçam como tais? Ao longo de seus 161 anos de fundação, Juiz de Fora - e, consequentemente, "seu povo"- vêm recebendo definições que, longe de delimitarem uma identidade fixa, refletem a fluidez simbólica com a qual a mesma é encarada. Àqueles que se dedicam a estudar as especificidades da identidade local, resta o desafio de lidar com as peculiaridades de um município que reforça sua identidade pela diferença em relação a outras localidades mineiras.

Conservadorismo e progresso marcam a identidade de Juiz de Fora. O município, considerado de porte médio, tem população estimada de pouco mais de 500 mil habitantes. É importante salientar sua função de principal cidade da Zona da Mata mineira e sua posição de polo regional que presta serviços no comércio, saúde e educação a habitantes de vários municípios, extrapolando, inclusive, fronteiras estaduais. Por outro lado, a cidade, quarto maior município mineiro em população, encontra-se tensionada entre as três maiores capitais brasileiras: São Paulo, Belo Horizonte e Rio de Janeiro.

Nesse contexto paradoxal, o que seria e a quem pertenceria Juiz de Fora? Por um lado, existe a cidade como uma "zona de glamour urbano" (GIDDENS, 2004, p. 572) um circuito de bons restaurantes e hotéis, edifícios de escritórios (alguns inclusive cobertos por painéis de artistas como Cândido Portinari), condomínios residenciais ${ }^{\mathrm{i}}$, shopping centers ${ }^{\mathrm{ii}}$, teatros e centros culturais, como o Cine Theatro Central e o Centro Cultural Bernardo Mascarenhas ${ }^{\text {iii. }}$.

Nos dois últimos há, frequentemente, por parte da mídia local, um discurso cosmopolita da cidade, que recebe nestes ambientes personalidades de renome nacional e até internacional com a valorização do local, daquilo que poderia ser caracterizado como "prata da casa", os artistas, personagens e personalidades regionais (sempre valorizados pelo reconhecimento nacional que obtiveram). 
Os exemplos mais recentes de valorização de artistas locais podem ser observados com a projeção midiática da cantora juizforana Josiane Oliveira, em função de sua participação no reality show da Rede Globo Big Brother Brasil 9, e da cantora Mylena, que ganhou projeção nacional depois de aparecer no quadro "Garagem do Faustão", que lhe rendeu inserção de canções nas novelas globais "Caras e Bocas" e "Malhação". Além disso, temos a participação de duas modelos juizforanas, Bruna Siqueira e Fernanda Moraes, no quadro "Garota Fantástica", do Fantástico, também na Rede Globo. O concurso visou eleger a top model mais profissional e bela do país.

Aliada a esse reconhecimento midiático de juizforanos, a valorização de pintores e escritores regionais confirmam a tese de Christina Musse (2006, p. 86) de que "a imprensa juizforana trata de intitular a cidade como a capital intelectual de Minas".

Jornalista, professora e pesquisadora das confluências entre comunicação, identidade, memória e imaginário urbano, Musse caracteriza Juiz de Fora como um caso particular de cidade mineira, principalmente por seu processo de povoação. Ela explica, em sua tese de doutorado, que a cidade não "viveu" com intensidade o ciclo do ouro. O desenvolvimento se fundamenta no mito (ainda sem consenso) dos imigrantes empreendedores e na realidade de sua efetiva identidade industrial, moderna e fabril no início do século XX e em declínio a partir de 1930, que rendeu ao município a designação de Manchester mineira, em comparação com a cidade inglesa.

[...] diferenças concretas que marcaram a ocupação da região, diferenciando-a do restante do estado de Minas Gerais e, em especial, revelando como a cidade, por não ter compartilhado sentimento barroco característico do período colonial mineiro, desta forma, se afastou daquilo que se convencionou chamar de discurso da "mineiridade", que forja a sua narrativa nos setecentos e oitocentos (MUSSE, 2006, p.46).

A relação de Juiz de Fora com a urbanização só acontece, de fato, após a abertura do Caminho Novo, estrada que encurtava a distância entre Rio de Janeiro e Minas Gerais, e se torna a principal via de entrada e de escoamento nas décadas finais do século XVIII, já no período do declínio do ouro. Quando trabalhamos a questão da 
formação da cidade, registra-se que Juiz de Fora ganha contornos de área urbana, ao se organizar como vila, somente no cafeicultor século XIX, e não no áureo e mineiro século XVIII .

$\mathrm{Na}$ Juiz de Fora de hoje, verificamos um domínio de estabelecimentos comerciais nas três principais vias da cidade, que também são as mais antigas: a Avenida Rio Branco, a Avenida Independência e a Avenida Getúlio Vargas. Bairros periféricos como Aeroporto e São Pedro abrigam construções luxuosas, refúgio dos cidadãos de classe média alta e alta. Contrapondo-se ao "glamour urbano da atual Manchester Mineira" temos uma outra população de "utilizadores da cidade" que cresce nas periferias (tanto territoriais quanto econômicas), cujas reivindicações à cidade são também legítimas, mas muitas vezes muito menos bem vindas.

No caso de Juiz de Fora, se, por um lado, a cidade apresenta em sua "cult-ura" a globalizante contribuição de influências alemãs, italianas, árabes e inglesas, da promoção de concertos internacionais de música erudita, das raves com nomes da cena eletrônica mundial, por outro ganha seu status regionalista com os vendedores de verduras nas portas das casas e carroças fazendo transporte de cargas nas avenidas centrais.

\section{As cidades e o desenraizamento dos quadros de referência}

A indefinição entre o cosmopolitismo e o provincianismo de Juiz de Fora torna ao mesmo tempo difícil e primordial a atribuição de uma identificação coletiva ao telejornalismo local. Tal identificação esbarra na constatação de que a "crise de identidade" proposta por Stuart Hall (2003) não se configura como sintoma exclusivo de nossa cidade-recorte. Nossas leituras nos permitem observar que, de maneira mais abrangente, as cidades na atualidade são desenraizadoras com relação às suas instituições, quadros de referência e convicções. O urbano é hoje tão fluído quanto a própria modernidade contemporânea e todos os seus elementos fugazes e contraditórios. $\mathrm{Na}$ direção desse pensamento, Irlys Alencar Barreira privilegia as diferentes conexões estabelecidas entre a cidade e seu passado, por meio de discursos múltiplos que 
dependem de (igualmente múltiplos) contextos e porta-vozes - como é o caso dos jornalistas.

Tendo como base de pesquisa a cidade de Fortaleza, a autora questiona a manutenção da cidade enquanto patrimônio, que para se efetivar necessita de investimentos materiais e simbólicos de toda a sorte. Interessa-nos, sobretudo, a observação da autora de que, quando se abordam questões como memória e patrimônio, os discursos sobre as cidades tentam forjar-se na efetivação de prioridades que aparentam uma construção coletiva, numa tentativa de mascarar o caráter intrínseco de disputas simbólicas que todo discurso fomenta. Ou seja, "a história ou memória da cidade, materializadas no conceito de patrimônio, expressam versões diferenciadas ou visões de um imaginário urbano, nem sempre convergentes" (BARREIRA, 2003, p. $315)$.

Nesse sentido, o passado - no nosso caso o de Manchester Mineira, Princesa de Minas ou muitos outros possíveis - para ser "vendido como discurso" pode ser projetado no presente como o "paraíso perdido", instrumento de reativação de costumes e reinvenção de tradições. Passado mitificado, idealizado, num tempo que não é repetido (embora alguns discursos o pretendam), mas reinventado, ressignificado.

Alencar toma como referência de estudos dois tipos de discurso: o da preservação e o da transformação planejada. No primeiro, tem-se a cidade embebida em nostalgia e romantismo, na voz de cronistas e escritores, na luta por se buscar "aquilo que já não se é mais". Aqui acontece também a crítica ao crescimento desordenado e vertiginoso da cidade, que constantemente percebemos em narrativas que incluem Fortaleza, Juiz de Fora e outras cidades. Já na "transformação planejada", observa-se uma valorização do "olhar do turista" sobre a cidade, como aquele que busca tradição mas necessita de boas "acomodações" - tanto físicas quanto discursivas. Exige-se preservação, controle e revitalização, ao mesmo tempo em que se apregoa uma "estética da diversidade", na opinião de planejadores e arquitetos. A municipalização do turismo motiva as cidades a buscarem "vocações específicas", como a vocação turística, no caso 
de Fortaleza, ou a vocação para a prestação de serviços e difusão cultural, como acontece com Juiz de Fora.

O papel das cidades como conjunto de representações a serem consumidas de acordo com determinadas "vocações” também é discutido por Maria Bernardete Ramos Flores e Emerson Campos. Em "Carrosséis urbanos: da racionalidade moderna ao pluralismo temático", os autores tentam demonstrar a polifonia simbólica envolvida na construção dos imaginários urbanos ou da "cidade imagem" (CAMPOS; FLORES, 2007, p. 269). Festas "populares", disputas étnicas e arquitetura, dentre muitos outros elementos discursivos possíveis são apresentados como "cavalos coloridos" presentes neste Carrossel urbano - termo felizmente utilizado pelos autores para dar conta da "proliferação vertiginosa de sinais, luzes e cores que a cidade contemporânea emite" (CAMPOS; FLORES, 2007, p. 291).

Segundo os autores, o modelo moderno de cidades, pautado na integração racional de territórios, não se sustenta na contemporaneidade. As manifestações culturais já não se prendem a lugares definidos. Prioriza-se a performatividade e a produção de imagens identificadoras, numa constante tensão entre lugar e identidade. Neste contexto, os moradores das cidades figuram como elemento de composição do cenário turístico, com corpos submetidos a normas para que se tornem códigos de determinadas tipificações.

Voltando ao âmbito local, é visível a justaposição de vidas e meios de vidas, na luta por uma re-descoberta de identidades juizforanas. Trata-se de algo que se reflete no telejornalismo e em sua audiência (ou na audiência que os jornalistas presumem ${ }^{\mathrm{iv}}$ ). Isso é percebido ao observarmos a tradição da mídia local de resgate de ordem, de desvelamento e demarcação dos problemas e "territórios" urbanos, seguindo uma tendência nacional, tendo-se na "voz do povo" e na priorização de matérias locais a materialização do cotidiano. 


\section{Telejornalismo e emissoras de produção local em Juiz de Fora}

Como a bancada por nós ocupada oferta uma pesquisa de recorte contemporâneo, partimos para a descrição atual ${ }^{\vee}$ dos três telejornais locais de horário noturno produzidos na cidade e que são foco deste trabalho.

A história da Rede Globo em Juiz de Fora começa em 1980, quando a TV Industrial encerra suas atividades e é vendida para o grupo de Roberto Marinho, em fase de expansão e desejando se instalar na região. Com a venda para a Globo Minas, a emissora passa a retransmitir o sinal da Rede Globo e a programação local da Rede Globo Juiz de Fora é reduzida a alguns minutos diários nos telejornais sediados em Belo Horizonte. De 1980 a 1998, a dependência da matriz no Rio de Janeiro foi intensa e o "padrão globo" é seguido rigorosamente. Em 1998, numa tentativa de resgate do local para enfrentar a globalização e atrair novos mercados publicitários, a TV Globo Juiz de Fora passa a se chamar TV Panorama. $\mathrm{O}$ estímulo à nova regionalização fez com que o espaço reservado ao telejornalismo local aumentasse de 15 minutos para aproximadamente 50 minutos diários. Os telejornais MGTV $1^{\mathrm{a}}$ e $2^{\mathrm{a}}$ edição passam a ser apresentados também no estúdio de Juiz de Fora, em interação com apresentadores da TV Globo Minas.

Estratégias comerciais fazem com que a Globo, em 2003, venda suas emissoras do interior. A TV Panorama é pioneira nesse processo, sendo vendida para o empresário Omar Resende Peres. Ex-secretário de Minas e Energia do estado de Minas Gerais (no governo Itamar Franco), ele torna a emissora o primeiro veículo do grupo de mídia que iria constituir, a OP.COM. Atualmente, a TV Panorama conta com uma produção local de aproximadamente seis horas semanais. $\mathrm{Na}$ somatória da produção local estão o Telejornal MGTV (com duas edições que totalizam 52 minutos diários, de segunda a sábado) e o programa Panorama Entrevista, veiculado aos domingos, com meia hora de duração.

A afiliada da TVE Rio entra no ar em 1981, a cargo da Fundação Educacional Pio XII. A emissora tornou-se geradora em 1989, mas nunca havia produzido telejornais 
até o ano de 2009. Após a morte e Josino Aragão, em 2008, a família opta também por admitir 12 estagiários estudantes da Faculdade de Comunicação da UFJF, que atuam na área de jornalismo da empresa. Em novembro de 2009, o jornal da TVE Juiz de Fora surge como uma nova promessa de espaço para a informação e discussão dos assuntos relativos aos acontecimentos da cidade e região. Exibido de segunda a sexta, a partir das 18:30, o telejornal tem cerca de 28 minutos de produto diário.

A TV Alterosa - terceira emissora local abordada nesta pesquisa - surge quando, em 1999, a TV Tiradentes é vendida para a TV Alterosa, afiliada ao Sistema Brasileiro de Televisão (SBT) ${ }^{\text {vi }}$. O Jornal da Alterosa (JA) edição regional, foi veiculado até 2009, de segunda a sábado, no horário do almoço (11:50), com duração em torno de 25 minutos. Em 8 de março de 2010, passa a ser veiculado, seguindo ordens da matriz de Belo Horizonte, das 19:20 às 19:45, inserindo-se no recorte desta pesquisa.

\section{Formatos de apresentação da notícia e da cidade nos telejornais}

A notícia ouvida no rádio, lida nos jornais ou assistida na televisão, ganha muito de sua configuração das características do próprio meio no qual ela aparece. Por isso, é primordial analisarmos as configurações da notícia como um gênero discursivo em relação às características que ela ganha quando elaborada para transmissão na televisão. Ou, nas palavras de Itânia Gomes (2007), o "pacto sobre o papel do jornalismo" se regula por acordos tácitos. Para a pesquisadora:

Os recursos técnicos a serviço do jornalismo, ou seja, o modo como as emissoras lidam com as tecnologias de imagem e som colocadas a serviço do jornalismo, o modo como exibem para o telespectador o trabalho necessário para fazer a notícia são fortes componentes da credibilidade do programa e também da emissora e importante dispositivo de atribuição de autenticidade (GOMES, 2007, p. 26).

A apresentação da notícia: em nota, reportagem, entrevista, indicador, editorial, comentário, resenha, crônica, caricatura; enquete, perfil, dossiê e cronologia dão importantes pistas sobre o tipo de jornalismo realizado pelos programas e, em certa 
medida, deixam transparecer o investimento do programa na produção da notícia, na perspectiva de Gomes. Para Coutinho (2003, p.107), o ritmo de edição, a frequência e forma de utilização de textos em off, passagens, entrevistas, sobe som "nos ajudam a identificar as características de linguagem de cada telejornal ou, em outros termos, as convenções narrativas adotadas por cada noticiário estudado".

Retomamos também François Jost (2004) e seu modelo de comunicação visual por meio da promessa, seja ela material ou simbólica, para definirmos nossa primeira unidade de classificação: o formato de apresentação da notícia. Jost (2004, p. 18) exemplifica a questão do formato, concluindo que "todos sabemos que uma comédia deve fazer rir; essa é sua promessa". Ou que, nas emissões ao vivo, existe a promessa de autenticidade maior do que em outros tipos de programa, daí a indicação na tela sobre o "ao vivo".

Nosso recorte abarca cinco edições de cada um dos três telejornais locais do horário noturno produzidos atualmente em Juiz de Fora - Jornal da Alterosa Edição Regional, MGTV 2a Edição e Jornal da TVE - no período de 3 a 7 de maio de 2010. Verificamos, de maneira geral, o predomínio das matérias de produção local, totalizando 77 produções - quase metade (48\%) de tudo aquilo que é produzido como material para os noticiários. As notas ao vivo representam o segundo maior "pacote narrativo" ofertado à população, com 48 ocorrências ou $30 \%$ das produções. Em seguida, temos as notas cobertas (18 notas ou $11 \%$ do total), as matérias de produção não local (13 matérias ou 8\%). Por fim, o formato menos utilizado foi o de entrevistas ao vivo em estúdio/via telão, com cinco ocorrências ou 3\% do total, sendo quatro delas registradas no Jornal da Alterosa Edição Regional e uma no Jornal da TVE.

Com imagens em externa e narração feita pelo repórter, as matérias ou videoteipes (VTs) são o formato mais elaborado para apresentação da notícia em um telejornal. Além de apresentar chances de construção de uma mensagem efetivamente audiovisual, já que imagem e som informam o telespectador, as matérias são elaboradas a partir da atuação de vários integrantes: o pauteiro/produtor; a equipe de reportagem. 
Matérias que abordam temáticas que dizem respeito a uma cidade (e somente a ela), seja esta Juiz de Fora ou não, foram agrupadas na categoria local. O interesse regional ou nacional pelo tema abordado justifica a classificação nestas outras categorias. Nestes casos, nosso exercício se concentrou em classificar as matérias em regionais e nacionais se - e somente se - no caso de determinada produção ser deslocada dos noticiários locais, sua estrutura narrativa permitisse a exibição em telejornais regionais e nacionais, respectivamente, sem maiores "riscos" de "aclimatação". Esse aproveitamento de matérias locais em nível regional e nacional é, inclusive, motivo de estímulo e júbilo para os profissionais locais, símbolo de reconhecimento do valor daquela informação.

Há, conforme observamos, pautas cuja temática têm interesse predominantemente local, sobretudo o dos moradores de Juiz de Fora. Na perspectiva compartilhada com Iluska Coutinho e Lívia Fernandes (2009, p. 93), na obra "Identidades midiáticas", observamos que "o local se torna um território audiovisual que é constituído por meio dos recortes e reconstruções de realidade transmitida nos telejornais locais". A proximidade pode, com isso, ser classificada como um valornotícia. Neste território, o telespectador se reconhece e convive com mensagens que constituiriam um repertório comum, capaz de "enlaçar" dada comunidade. Em análise focada nos dois telejornais existentes em Juiz de Fora (MGTV e Jornal da Alterosa, já que o Jornal da TVE ainda estava por surgir no período desta pesquisa, que vai de 2004 a 2007), os autores ressaltam que, apesar de os dois telejornais serem apresentados como produtos de jornalismo regional, a maioria das matérias produzidas e veiculadas têm cunho local. A pesquisa apresentada neste artigo atualiza, quantifica e qualifica tais questionamentos e inclui neste cenário o telejornal da TVE.

Quando o assunto é produção local aliada às temáticas locais, temos no Jornal da Alterosa o cenário onde essa categoria alcança seu maior índice, incluindo $88 \%$ de todas as matérias produzidas localmente. Problemas de bairro e ocorrências policiais encabeçam as produções do tipo no Jornal da Alterosa. Os responsáveis pela produção noticiosa tentam, ao longo de cada edição, costurar sua relação com a audiência 
predominantemente por meio de demarcações identitárias definidas pelos bairros, ruas e avenidas juizforanos. É o caso de 10 das 25 matérias - o que equivale a $40 \%$ de produção local com enfoque local presente em nosso recorte. Matérias cujas chamadas são anunciadas pela âncora das seguintes maneiras: "Polícia militar fecha o cerco ao tráfico de drogas no bairro Vila Olavo Costa, em Juiz de Fora" (03/05/10); "Moradores da Zona Norte em Juiz de Fora pedem providências. Eles temem a falta de segurança da Curva da Miséria, que já provocou inúmeros acidentes" (03/05/10); "Assaltantes invadem uma loja na Zona Leste de Juiz de Fora e levam todo o dinheiro do caixa" (04/05/10); “25 Km/h. Esta é a velocidade que os ônibus de Juiz de Fora, que trafegam no trecho entre a Independência e a Getúlio Vargas, terão de respeitar" (05/05/10); “Um ladrão invadiu um apartamento na Zona Sul de Juiz de Fora nessa tarde" (06/05/10); “Os buracos são problemas constantes na vida dos moradores do bairro Barbosa Lage" (06/05/10); "Prevenção de acidentes na Zona Sul de Juiz de Fora. Dicas de trânsito seguro foram distribuídas em vários bairros" (06/05/10); "Tiroteio na Zona Leste de Juiz de Fora. Um mecânico foi alvejado, como mostra a repórter Michele Pacheco" (07/05/10); "Uma caixa d'água abandonada tem dado dor de cabeça aos moradores do Bairro Santa Rita” (07/05/10); “o Jornal da Alterosa vai homenagear todas as mulheres que se dedicam de corpo e alma aos seus filhos, aproveitando a lição de vida de uma mãe que mora no Bairro Santa Rita, em Juiz de Fora” (07/05/10).

No Jornal da TVE, temos 26 das 35 matérias, ou 74\% do material com produção local, cuja temática se restringe a uma localidade/município. O laço social (WOLTON, 1996) que a emissora tenta forjar com seu público se alicerça principalmente nas matérias de bairro juizforanos. Os bairros - e seus moradores - são apresentados em matérias "leves", sob uma narrativa mais estendida em relação ao tempo, se comparada aos tempos de fala dos personagens inseridos nos outros dois telejornais de nossa análise. A justificativa de que, dos três telejornais estudados, o Jornal da TVE se configura como aquele com maior tempo de produção (edições diárias de aproximadamente 30 minutos de conteúdo jornalístico, diante dos 12 minutos do MGTV2 e do Jornal da Alterosa com 20 minutos), não nos parece ser o único fator 
responsável por esse "alongamento" do momento de fala do cidadão comum, da "voz do povo".

O cotidiano é delineado nesse telejornal reavivando características da "Manchester Mineira" ou da "Princesa de Minas", com cidadãos reafirmando tais discursos em 18 das 26 matérias produzidas localmente e com enfoque local, ou $70 \%$ : "Gráfica em Juiz de Fora começa a fazer impressos em braile" (03/05/10); "Dia do trabalho é comemorado no Sesc de Juiz de Fora" (03/05/10); "Benfica Esporte Clube comemora 73 anos" (03/05/10); "Projeto Meu Bairro: Clube Juiz de Fora Bola Show, no Bairro Santa Luzia" (03/05/10); "Encontro de comunidades da PM de Juiz de Fora" (04/05/10); "Benefícios da ginástica laboral" (04/05/10); "Funcionamento do SAMU de Juiz de Fora" (04/05/10); "Banco de Leite de Juiz de Fora realiza encontro de mães" (06/05/10); "Visita da Confederação Brasileira de Desporto a Juiz de Fora" (07/05/10); "Missa das mães em Juiz de Fora" (07/05/10); "Projeto meu bairro/Santa Luzia: Homenagem à Dona Lira" (07/05/10). Além disso, na semana-recorte, temos oito matérias em comemoração aos 160 anos de Juiz de Fora, em que a população e personalidades da cidade aparecem dando seus parabéns ao município.

O MGTV $2^{\mathrm{a}}$ Edição ofereceu, na semana de nossa pesquisa, $76 \%$ de matérias produzidas localmente com enfoque local, ou 13 produções do tipo, Nas matérias locais, o factual - com ênfase nas mazelas da população de Juiz de Fora e região (sete das 13 matérias, ou 53,8\%) - se mescla a um tom que prioriza o enquadramento econômico, com seis matérias ou 46,15\% da produção local de matérias. Tem-se dessa maneira matérias factuais, que tentam firmar com a audiência um vínculo estabelecido por meio da identificação (ou catarse) com os problemas enfrentados pelos personagens na narrativa, como: "Crise no Pronto Socorro de Juiz de Fora" (03/05/10); "Queda de barranco em Silveirânia" (03/05/10); "Aumentam reclamações contra bancos" (04/05/10); "Motoboys temem assaltos em bairros de Juiz de Fora" (05/05/10); "Comer fora em Juiz de Fora está mais caro" (06/05/10); “Aumentam reclamações contra operadoras de telefonia em Cataguases" (07/05/10) e "SUS demora a liberar exames" (07/05/10). 
Nas matérias de economia com cunho local temos: "Comércio aumenta vendas com Dia das Mães" (04/05/10); "Indústrias investem em tecnologia" (05/05/10); Mercado de flores em Barbacena para o Dia das Mães" (05/05/10); "Cresce venda de imóveis na planta em Juiz de Fora" (06/05/10); “Aumentam as vendas de notebooks em Juiz de Fora" (07/05/10); "Mercado de livros em Juiz de Fora" (06/05/10).

Interessante observar que, mesmo nas matérias factuais, nas hard news, o tom econômico é mantido como subtemática. No decorrer das histórias ofertadas, a abordagem das mazelas vivenciadas pelos personagens no MGTV2 tece íntima ligação com temáticas econômicas: os motoboys que temem assaltos em Juiz de Fora estão indiscutivelmente relacionados com o aumento das entregas em domicílio na cidade. Se comer fora em Juiz de Fora está mais caro, descortina-se aqui um cenário onde a população (ou ao menos a audiência que se presume população), embora reconheça o ônus de comer em restaurantes, está saindo de casa para isso. As reclamações contra operadoras de telefonia em Cataguases levam-nos para "locações" onde as vítimas embora vítimas - das operadoras, simbolizam também o crescimento vertiginoso das vendas de aparelhos celulares no Brasil, com os prós e contras que se amarram a esta constatação. A predominância da temática econômica na observação posterior de outras edições não contempladas em nosso recorte, aliada ao caráter econômico de matérias cuja narrativa poderia facilmente seguir outro tom que não esse, nos fazem crer, ainda, que a coincidência de nosso recorte com a proximidade do Dia das Mães pouco afetou o caráter econômico da política editorial adotada pela equipe.

\section{Considerações finais}

Mais do que três telejornais distintos, é possível dizer que observamos uma nítida delimitação de três "Juiz de Foras" que são ofertadas pelos discursos audiovisuais locais. Esses discursos são ancorados, cada qual, em justificativas editoriais mais ou menos definidas e oferecidas como "promessas de cidade" ao telespectador. Neste contexto, as narrativas televisivas se transformam em recursos simbólicos que podem orientar a formulação de representações e identidades. 
Podemos considerar, no caso do Telejornal da Alterosa, uma representação de cidade atuando de maneira afinada com o discurso da equipe, de desvelamento das mazelas urbanas e cobrança pela instauração da ordem em meio ao caos genérico. Um telejornal que surge tributário da matriz SBT e segue padrões discursivos do "Aqui Agora", tenta incorporar, ao longo do tempo, traços de mineiridade e de juizforaneidade para, mais tarde, trazer à tona recursos do passado "mítico" da emissora de Sílvio Santos. A ligação com o universo do popular e as matérias de denúncia se incluem neste pacote. O MGTV $2^{a}$ Edição surge neste panorama ofertando com especial frequência uma cidade que é mais consumidora do que cidadã, para citarmos Canclini (2001), e precisa de um "dicionário de mazelas" que lhe explique a realidade, mais que de um megafone que amplifique sua voz e problemas em tela. E que fique claro aqui que nosso apontamento de diferentes posturas com relação à população vítima nestes telejornais não denota uma preferência pela postura "econômico-explicativa" de um ou denunciativa de outro. Até porque compartilhamos com Canclini a ideia de consumo como fator de construção de uma marca de pertencimento. Ao despender bens materiais ou simbólicos, mais do que serem enquadrados como vorazes consumidores de superficialidades e objetos de manipulação da economia capitalista, os consumidorestelespectadores estariam tecendo as malhas do tecido social a que pertencem ou desejam pertencer, criando sua identidade e sua narrativa sobre a cidade.

Recém-nascido em termos de exibição, o que não quer dizer "inocente" em termos de elaboração de discurso, temos o Jornal da TVE e sua apresentação de/para o público. A cada edição, mais do que denunciar, ou investigar, anunciar as coisas, as belas coisas. As matérias de celebração, as soft news e a apresentação de boas atitudes e notícias leves tentam forjar este cenário. Embora queira, indubitavelmente, um público pra chamar de seu, o telejornal da TVE busca, antes deste, uma "identidade pra chamar de sua". 


\section{Referências}

BARREIRA, Irlys Alencar F. A cidade no fluxo do tempo: invenção do passado e patrimônio. Sociologias, Porto Alegre, n. 9, p.314-339, jan. 2003.

CAMPOS, Emerson César de e FLORES, Maria Bernardete Ramos. Carrosséis urbanos: da racionalidade moderna ao pluralismo temático (ou territorialidades contemporâneas). Revista Brasileira de História, São Paulo, v.27, n.53, Jan./Jun. 2007.

COUTINHO, Iluska. Dramaturgia do telejornalismo brasileiro: a estrutura narrativa das notícias em TV. Tese (Doutorado em Comunicação Social). Universidade Metodista de São Paulo. São Bernardo do Campo, 2003.

GARCÍA CANCLINI, Nestor. Consumidores e cidadãos: conflitos multiculturais da globalização. Tradução: Maurício Santana Dias. 6 ed. Rio de Janeiro: Editora UFRJ, 2001.

GIDDENS, Anthony. Sociologia. Lisboa: Fundação Calouste Gulbenkian, 2004.

. Modernidade e identidade. Rio de Janeiro: Jorge Zahar Editor, 2002.

GOMES, Itânia Maria Mota. Das utilidades do conceito de endereçamento para análise do telejornalismo. Rio de Janeiro: e-papers, 2007.

HALL, Stuart. Identidade cultural na pós-modernidade. Trad. Tomaz Tadeu da Silva, Guacira Lopes Louro. 7.ed. Rio de Janeiro: DP\&A, 2003.

JOST, François. Seis lições sobre a televisão. Porto Alegre: Sulina, 2004.

LAHNI, Cláudia Regina; MUSSE, Christina in COUTINHO, Iluska et al. Comunicação: tecnologia e identidade. Rio de Janeiro: Mauad X, 2007.

MUSSE, Christina Ferraz. Imprensa, cultura e imaginário urbano: exercício de memória sobre os anos 60/70 em Juiz de Fora. Tese de Doutorado. Escola de Comunicação da UFRJ. Rio de Janeiro, 2006.

SILVA, Tomaz Tadeu da. A produção social da identidade e da diferença. In: SILVA, Tomaz Tadeu da (Org.). Identidade e diferença. Petrópolis: Vozes, 2002.

VIZEU, Alfredo Eurico. Telejornalismo: a nova praça pública. Florianópolis: Insular, 2006.

WOLTON, Dominique. Elogio do grande público: uma teoria crítica da televisão. São Paulo: Ática, 1996.

Este artigo e todo o conteúdo da Estudos em Jornalismo e Mídia estão disponíveis em http://www.periodicos.ufsc.br/index.php/jornalismo/index

Estudos em Jornalismo e Mídia está sob a Licença Creative Commons 


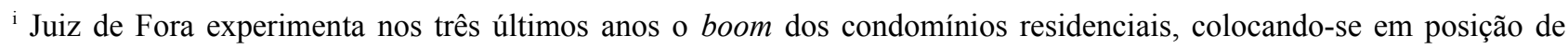
reivindicação de status dos grandes centros urbanos. Infinity e Play são alguns dos sugestivos nomes de condomínios oferecidos às classes média e alta da cidade, em bairros considerados nobres. A publicidade destas construções invade a mídia local atualmente, sugerindo um "american way of life" que vai além dos nomes: trata-se da tentativa de incorporação do estilo de vida das grandes cidades, onde (por questões como violência, trânsito e falta de tempo) o lazer, antes vivenciado em praças e ruas, dá lugar ao "playground", às salas de jogo e salões de eventos nos próprios prédios.

${ }^{i i}$ Merece destaque a implantação, no ano de 2008, do Independência Shopping, que agora passa a ser o maior da cidade e abriga lojas com marcas de renome nacional e internacional. O Shopping, instalado em local que estimulou inclusive a construção dos "vizinhos" condomínios supracitados, aparece na mídia local como símbolo de status e progresso, mas também como ameaça ao comércio da região central.

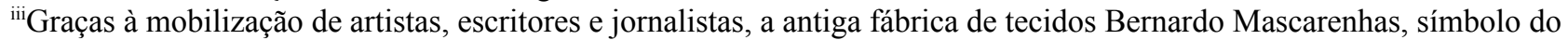
pioneirismo industrial, foi transformada, em 1987, no Centro Cultural Bernardo Mascarenhas (CCBM). Inserido na lista dos patrimônios mais populares do município, o CCBM oferece à comunidade galerias de arte, anfiteatro, videoteca, eventos musicais e salas de aula (onde são ministrados cursos de artes como desenho, artesanato e escultura).

${ }^{\text {iv }}$ A hipótese de Audiência Presumida, na concepção do professor e pesquisador na Graduação e na Pós-Graduação em Comunicação da UFPE Alfredo Vizeu, pode ser anunciada como a construção antecipada da audiência a partir da cultura profissional, da organização do trabalho, dos processos produtivos, dos códigos particulares (as regras de redação), da língua e das regras do campo das linguagens para, no trabalho da enunciação, produzirem discursos. Esse trabalho resultaria, nesse contexto, na notícia.

'Para detalhamento da história da televisão em Juiz de Fora, consultar: FERNANDES, Lívia. TV Mariano Procópio: representação e pioneirismo na história audiovisual de Juiz de Fora. Rio de Janeiro: E-papers, 2008.

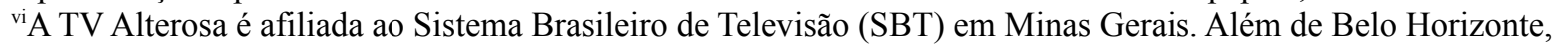
Divinópolis, Varginha e Juiz de Fora são os municípios com sede da TV Alterosa. As três emissoras do interior são dirigidas por Gleizer Naves. 